REVIEWARTICLE

\section{Barriers to Health Care for Children with Orofacial Clefts: A Systematic Literature Review and Recommendations for Research Priorities}

\author{
Nichole Nidey ${ }^{1}$ and George L. Wehby ${ }^{2 *}$ \\ ${ }^{1}$ Department of Epidemiology, University of lowa, US \\ ${ }^{2}$ Departments of Health Management and Policy, Economics, and Preventive and Community \\ Dentistry, and Public Policy Center Research Associate, National Bureau of Economic Research, \\ University of lowa, US
}

\begin{abstract}
Background: There is a growing interest in health services research of orofacial clefts (OFC) in the United States. The objective of this study is to summarize the empirical knowledge to date about barriers to health care for children with OFC.
\end{abstract}

Methods: We completed a systematic literature review to identify articles on barriers to healthcare for children with OFC in the United States. Pubmed, Embase, CINAHL, and Medline were searched from their dates of origin through June 2018 using a combination of key terms related to access and barriers to health care. Case reports and studies of populations outside of the United States were excluded.

Results: 4079 publications were identified using our search strategy. After a title and abstract review, 18 were included in our review as they met inclusion criteria. These studies examined health care costs, health insurance coverage, access to team care, geographic barriers, adequacy of training of community-based providers in providing services to children with OFC, and socioeconomic and demographic factors. The key findings indicate much higher health care costs for children with OFC than unaffected children early in childhood, racial/ethnic disparities in certain access measures, and inadequate insurance coverage, distance to teams, and inadequate training of community-based providers in OFC-specific services as potential areas of concern. Except for studies on health care costs, the evidence is largely based on relatively small and primarily descriptive studies.

Conclusions: The extant literature documents high health care costs for OFC treatments and suggests inadequate insurance coverage, long distance to cleft teams, and racial/ethnic disparities as critical factors related to access. We discuss multiple future research priorities. Among these, understanding the impacts of variation between states in mandates for private insurance benefits and generosity in Medicaid coverage on access to care as well as effects of differences in provider reimbursements are particularly understudied areas that can be meaningful for policy making aimed at improving access and health outcomes of children with OFC. Examining access throughout childhood and later in life and employing robust designs and population-representative data are also important research and methodological extensions of the current literature.

\section{Keywords}

orofacial clefts, barriers to care, access to care, literature review

\section{Introduction}

Orofacial clefts (OFC) are among the most common birth defects ${ }^{1}$. In the United States, the 
prevalence estimate is 1 in 600-700 births, although it may vary based ongeographic, socioeconomic status and ethnicity ${ }^{2-4}$. OFC can occur alone (isolated forms) or with other minor or major birth defects or as part of syndromes (non-isolated forms) $)^{5}$. Typically, for children with OFC, primary surgical repair of the lip is completed within the first year and cleft palate repair by 18 months of age ${ }^{6}$. In addition, depending on the severity of the cleft and if it presents with other medical conditions, difficulties with feeding, speech, hearing, and dental health can be present and may be common. These conditions increase the need for multiple health care services throughout the lifespan ${ }^{7}$. For example, additional surgeries, dental treatments, speech therapy, and psychosocial services are commonly needed and recommended through out childhood, adolescence and can extend into early adulthood ${ }^{6}$. Recent studies also have reported increased risk of certain behavioral problems as well as reduced academic achievement compared to classmates or children without birth defects. These finding highlight the additional potential effects on health and wellbeing of children, and the impacts OFC has over the course of the lifespan ${ }^{8-11}$.

The intensive medical treatments needed for children with OFC can create a financial and emotional burden on affected families. Previous studies have shown an increase in the days hospitalized, service costs and out-of-pocket costs related to OFC care can create financial stress on families ${ }^{12-14}$. Furthermore, parents may experience emotional strain during their child's course of treatment, particularly low-income parents who report lower self-esteem and reduced perception of social support than parents with higher income ${ }^{15,16}$. OFC can impact the quality of life of both affected individuals and their families in several ways ${ }^{11,17-20}$. The increased need for health care services, associated costs, and barriers to accessing care can have adverse impacts on families. However, research remains fairly scan ton barriers to health care for children with OFC ${ }^{21-23}$. Understanding health care costs and the role of insurance coverage in access to care for affected individuals have been identified as public health research priorities $^{24}$. However, despite some studies summarized below, there has been little research using large-scale, population-based datasets for examining the type and magnitude of barriers to care. In this paper, we summarize the current knowledge about cost, access, utilization and barriers to health care for children with OFC by systematically reviewing previous published studies that directly address this topic for populations in the United States. Based on this review, we identify and discuss the main research gaps and suggest future research priorities.

\section{Methods}

PubMed, EMBASE, CINAHL and Medline were searched from their date of origin through June 2018 for related publications. The following medical subject headings (MeSH), keywords and combinations of were used in all databases: cleft, health coverage, insurance, out of pocket, Medicaid, fee for service, speech, access, barriers, orthodontics, dental, hearing, genetic counseling or services, surgery, and therapy.

Observational studies of access and barriers to health care among individuals and their families were included in this study. Studies were excluded if they did not include populations from the United States, were case studies or reports, and if they were solely focused on clinical care techniques. Studies were identified by reviewing abstracts and titles by one investigator (NLN). Identified studies were reviewed for duplicates. All identified studies were published in English. Reference lists of included studies were reviewed for additional publications. Only published studies were included in the analysis, and grey/fugitive literature was not searched.

\section{Results}

A summary of our literature search is presented in Figure 1. Using PubMed, EMBASE, CINAHL and Medline we identified 4079 publications. A review of titles excluded 3975 publications. A majority of studies were excluded because they were related to clinical care practices and etiologies related to OFC or other conditions. Of the remaining 103 studies, 19 were included based on the inclusion criteria and full text review. We summarize the key findings we identified from these studies below under broad areas including cost of care, health insurance coverage, access to team care, training of community-based providers, and socio demographic factors. Table 1 summarizes the 18 included studies in this review including population, sample size, data source, and main findings. 
Figure 1: Systematic Review Results

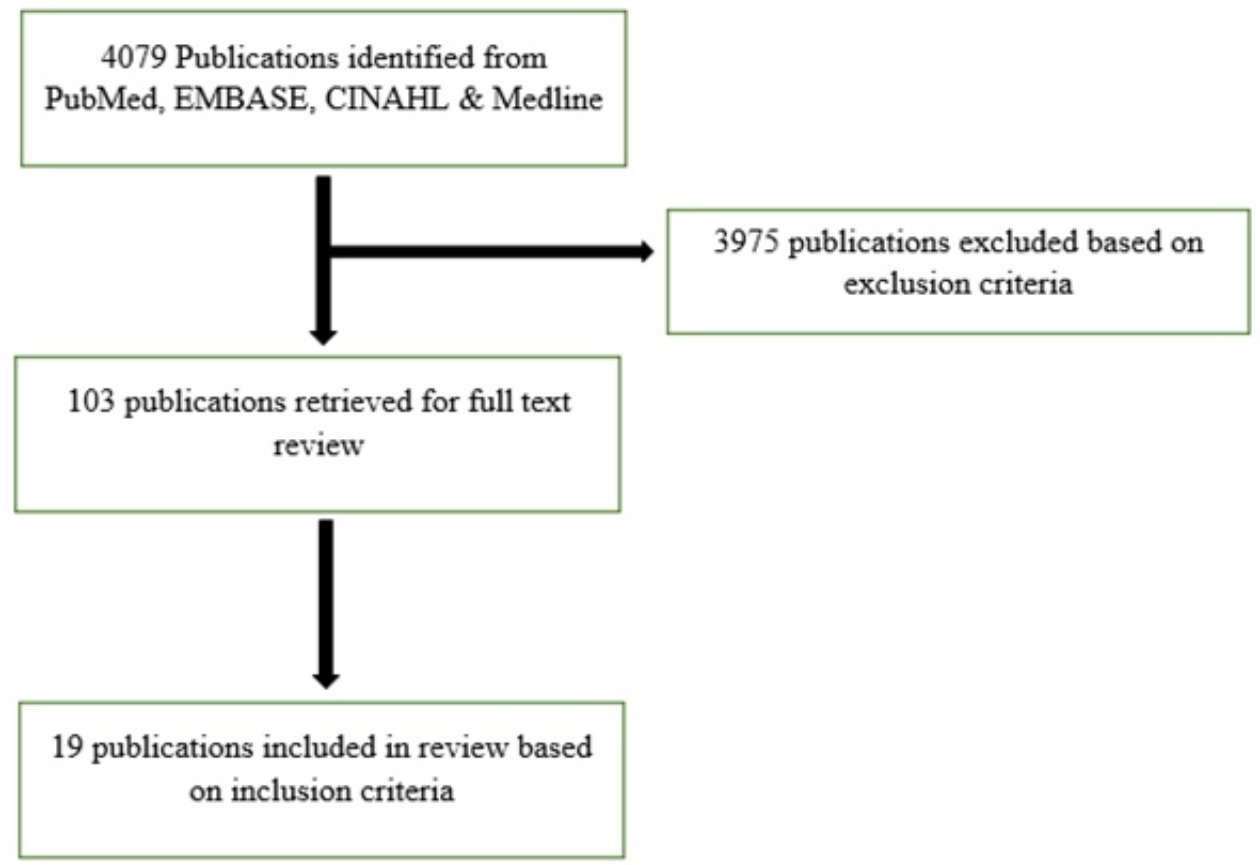

Table 1: Summary of Studies Identified in Literature Review

\begin{tabular}{|c|c|c|c|c|}
\hline Author, YR & Study Population & Sample Size & Data Source & Main Findings \\
\hline $\begin{array}{l}\text { Abott, et al. } \\
2011^{30}\end{array}$ & $\begin{array}{c}\text { Children }<24 \text { months of } \\
\text { age with nonsyndromic oral } \\
\text { cleft receiving cleft palate } \\
\text { repair }\end{array}$ & 4,247 & National database & $\begin{array}{l}\text { Age at cleft palate repair surgery is delayed for } \\
\text { children who have CLP vs. CPO and nonwhite } \\
\text { race/ethnicity or publicly insured }\end{array}$ \\
\hline $\begin{array}{l}\text { Al Agili, et al. } \\
2004^{21}\end{array}$ & $\begin{array}{l}\text { Parents of children age 3- } \\
13 \text { yrs. of age with CLP, } \\
\text { CPO*, other craniofacial } \\
\text { disorders, spina bifida, } \\
\text { cerebral palsy, } \\
\text { epilepsy/seizure disorders }\end{array}$ & $\begin{array}{l}714(24 \% \\
\text { OFC) }\end{array}$ & $\begin{array}{l}\text { Children's Rehabilitation } \\
\text { Services of Alabama }\end{array}$ & $\begin{array}{l}\text { Knowledge of caring for children with special health } \\
\text { care needs and low provider participation in } \\
\text { Medicaid program reduced access to dental care }\end{array}$ \\
\hline $\begin{array}{l}\text { Basseri, et al. } \\
\qquad 2011^{27}\end{array}$ & $\begin{array}{l}\text { Children with OFC } \\
\text { discharged from hospitals } \\
\text { from } 1997-2007\end{array}$ & $\begin{array}{c}45,676 \\
\text { discharges }\end{array}$ & Kids' Inpatient Database & $\begin{array}{c}\text { OFC patients often receive care at teaching } \\
\text { hospitals where they incur higher costs but less } \\
\text { complications }\end{array}$ \\
\hline $\begin{array}{l}\text { Becker, et al. } \\
\qquad 2009^{31}\end{array}$ & $\begin{array}{l}\text { Parents of children with } \\
\text { clefts born between } 1992- \\
1996 \text { and cared for at St. } \\
\text { Louis Children's Hospital }\end{array}$ & 171 & Subject interviews & $\begin{array}{c}\text { Patients insured by Medicaid had more difficulty } \\
\text { obtaining dental care }\end{array}$ \\
\hline $\begin{array}{l}\text { Boulet, et al. } \\
\qquad 2009^{25}\end{array}$ & $\begin{array}{l}\text { Children }<10 \text { years old } \\
\text { who were continuously } \\
\text { enrolled in private health } \\
\text { insurance }\end{array}$ & $\begin{array}{l}859 \text { cases }+ \\
820,760 \\
\text { controls }\end{array}$ & $\begin{array}{l}\text { MarketScan Commercial } \\
\text { Claims \& Encounters } \\
\text { databases }\end{array}$ & $\begin{array}{l}\text { Privately insured children with OFC have higher } \\
\text { medical costs than children without OFC. }\end{array}$ \\
\hline $\begin{array}{l}\text { Brown, et al. } \\
\qquad 2011^{38}\end{array}$ & $\begin{array}{l}\text { Orthodontic residents in US } \\
\qquad \& \text { Canada }\end{array}$ & 135 & Surveys & $\begin{array}{l}\text { Providers least positive about treating patients } \\
\text { insured by Medicaid and do not have an intent to } \\
\text { treat Medicaid or craniofacial patients }\end{array}$ \\
\hline $\begin{array}{l}\text { Cassell, et al. } \\
\qquad 2008^{26}\end{array}$ & Children born 1995-2002 & $\begin{array}{l}1,252 \text { cases }+ \\
6,127 \text { controls }\end{array}$ & $\begin{array}{l}\text { North Carolina vital statistics } \\
\text { and Medicaid claims }\end{array}$ & $\begin{array}{l}\text { Higher Medicaid expenditures were observed } \\
\text { among children with OFC compared to children } \\
\text { without. }\end{array}$ \\
\hline $\begin{array}{l}\text { Cassell, et al. } \\
\qquad 2009^{29}\end{array}$ & $\begin{array}{l}\text { Children born between } \\
\text { 1995-2002 who are North } \\
\text { Carolina residents enrolled } \\
\text { in Medicaid }\end{array}$ & 406 & $\begin{array}{l}\text { North Carolina Vital } \\
\text { Statistics, birth defects } \\
\text { registry and Medicaid files }\end{array}$ & $\begin{array}{c}\text { Non-Hispanic Black children less likely to have } \\
\text { surgery by } 18 \text { mo of age and children in the } \\
\text { southwestern perinatal care region less like to have } \\
\text { timely surgery }\end{array}$ \\
\hline $\begin{array}{l}\text { Cassell, et al. } \\
\qquad 2013^{22}\end{array}$ & $\begin{array}{l}\text { Children born between } \\
2001-2004 \text { with a cleft } \\
\text { identified by the birth } \\
\text { defects registry in North } \\
\text { Carolina }\end{array}$ & 245 & Mail \& phone survey & $\begin{array}{l}\text { Overall, travel time and distance were not identified } \\
\text { as barriers to care }\end{array}$ \\
\hline
\end{tabular}




\begin{tabular}{|c|c|c|c|c|}
\hline $\begin{array}{l}\text { Cassell, et al. } \\
\qquad 2012^{28}\end{array}$ & $\begin{array}{l}\text { Mothers of infants born in } \\
\text { North Carolina identified by } \\
\text { the North Carolina Birth } \\
\text { Defects Monitoring } \\
\text { Program }\end{array}$ & 98 & Survey questions & $\begin{array}{l}\text { Personal, structural and financial barriers were } \\
\text { perceived as the main barriers to accessing cleft } \\
\text { care }\end{array}$ \\
\hline $\begin{array}{l}\text { Cassell, et al. } \\
\qquad 2009^{26}\end{array}$ & $\begin{array}{l}\text { Children born 1995-2002 } \\
\text { continuously enrolled in } \\
\text { Medicaid }\end{array}$ & $\begin{array}{l}1,252 \text { cases }+ \\
6,127 \text { controls }\end{array}$ & $\begin{array}{c}\text { North Carolina vital statistics } \\
\& \text { birth defect registry and } \\
\text { Medicaid enrollment \& paid } \\
\text { claims }\end{array}$ & $\begin{array}{l}\text { OFC is associated with higher Medicaid } \\
\text { expenditures compared to children without OFC }\end{array}$ \\
\hline $\begin{array}{l}\text { Damiano, et al. } \\
\qquad 2010^{36}\end{array}$ & $\begin{array}{l}\text { Primary care physicians in } \\
\text { AK, IA, NY who treat } \\
\text { children with OFC }\end{array}$ & 1,435 & Surveys & $\begin{array}{l}\text { Lack of experience treating children with OFC } \\
\text { creates a barrier to care }\end{array}$ \\
\hline $\begin{array}{l}\text { Lewis, et al. } \\
\qquad 2005^{37}\end{array}$ & $\begin{array}{l}\text { Orthodontists in } \\
\text { Washington state }\end{array}$ & 156 & Surveys & $\begin{array}{l}2 \% \text { of patients enrolled in Medicaid, } 20 \% \text { treated at } \\
\text { least } 3 \text { patients with OFC in the past } 3 \text { years }\end{array}$ \\
\hline $\begin{array}{l}\text { Lynn, et al. } \\
2018^{43}\end{array}$ & $\begin{array}{l}\text { Patients with oral clefts } \\
\text { born } 2001-2014 \text { who have } \\
\text { had CL/P surgical repair }\end{array}$ & 178 & Medical records & $\begin{array}{l}\text { The following characteristics are associated with } \\
\text { missed appointments: black, Medicaid enrolled, } \\
\text { unstable background, unstable social background, } \\
\text { received need-based financial assistance }\end{array}$ \\
\hline $\begin{array}{l}\text { Noble, et al. } \\
2010^{39}\end{array}$ & $\begin{array}{l}\text { Orthodontic residents in US } \\
\text { \& Canada }\end{array}$ & 180 & Surveys & $\begin{array}{c}53 \% \text { of US residents plan to treat patients with } \\
\text { OFC after graduation and } 82 \% \text { of US residents } \\
\text { reported their program offered training on caring for } \\
\text { patients with OFC }\end{array}$ \\
\hline $\begin{array}{l}\text { Razzaghi, et al. } \\
\qquad 2015^{13}\end{array}$ & $\begin{array}{l}\text { Children with OFC born } \\
1998-2006\end{array}$ & 2,129 & $\begin{array}{l}\text { Hospital discharge, Florida } \\
\text { Birth Defects Registry }\end{array}$ & $\begin{array}{l}\text { Cleft palate only compared to other OFC subtypes } \\
\text { is associated with greater use of hospital resources }\end{array}$ \\
\hline $\begin{array}{l}\text { Silvestre, et al. } \\
\qquad 2017^{42}\end{array}$ & $\begin{array}{l}\text { Patients with nonsyndromic } \\
\text { oral clefts }\end{array}$ & 233 & Medical records & $\begin{array}{l}\text { Hispanic and African American children have } \\
\text { delayed timing of alveolar bone grafting surgery }\end{array}$ \\
\hline $\begin{array}{l}\text { Weiss, et al. } \\
\qquad 2009^{14}\end{array}$ & $\begin{array}{c}\text { Children alive at age two } \\
\text { with at craniofacial } \\
\text { malformation (include OFC) } \\
\& \text { children without } \\
\text { craniofacial malformations }\end{array}$ & $\begin{array}{l}649 \text { cases }+ \\
377,381 \\
\text { controls }\end{array}$ & $\begin{array}{l}\text { Massachusetts Pregnancy } \\
\text { to Early Life Longitudinal } \\
\text { Data System, } \\
\text { Massachusetts Birth Defects } \\
\text { Monitoring Program }\end{array}$ & $\begin{array}{l}\text { Hospital costs are higher among children with } \\
\text { craniofacial malformations }\end{array}$ \\
\hline $\begin{array}{l}\text { Vallino, et al. } \\
\qquad 2008^{41}\end{array}$ & $\begin{array}{l}\text { graduate program } \\
\text { representatives for speech- } \\
\text { language pathology } \\
\text { students }\end{array}$ & 232 & Questionnaire data & $\begin{array}{c}\text { Graduate students have little training and exposure } \\
\text { related to OFC }\end{array}$ \\
\hline
\end{tabular}

\section{Cost of Care}

As mentioned above, children with OFC face greater health care needs related to surgical repair and other health care interventions than the general population of children. Prior research had made important contributions to our understanding of the cost of care related to OFC. Previous studies document greater health care costs among children with OFC ${ }^{13,14,25,26}$. Focusing on children aged 10 or younger covered in employer-sponsored plans and using Market Scan data from 2000-2004, Boulet et al. (2009) estimated that total health care costs (including inpatient and outpatient services and prescription drug costs) of children with OFC exceeded those of children without an OFC by about eight times or $\$ 13,000$ annually ${ }^{25}$. The difference was largest in the first year of life by over $\$ 80,000$ per child on average, mostly due to initial surgical corrections of the cleft but declined to under $\$ 5,000$ (per year) by age three years and older.

Children with non-isolated OFC had greater health care costs than those with isolated OFC by about five times on average, with the largest difference in the first year of life, an average difference of about $\$ 170,000$. This study, however, did not include out-of-pocket expenses and findings were only generalizable to children with employer-sponsored coverage represented in the Market Scan dataset, which is a limitation of this study. Furthermore, exclusion of costs related to dental care underestimates the total health care cost differences when comparing children with OFC to children without an OFC because of the greater need for dental interventions and since these services are not necessarily covered in medical insurance plans. Cassell et al. (2008) examined differences in health care expenditures between children with and without OFC enrolled in the North Carolina Medicaid program, using birth defects registry and Medicaid data from 1995-2002 ${ }^{26}$. The authors found total Medicaid expenditures among children with OFC exceeded those of children without OFC by about $\$ 19,000$, almost six times higher, during the first year of life. Similar to privately covered 
children with OFC, expenditures among children with non-isolated OFC were higher than those with isolated OFC by about five times. Differences in expenditures between children with and without OFC declined to about $\$ 5,000$ by age five years. No data were included however on out-of-pocket costs for non-covered services, such as equipment or appliances. As a result, it is unclear how out-of-pocket expenses may burden families. Furthermore, individuals with OFC require care throughout their lifespan, however differences in expenditures were only estimated for up to age five in this study.

Differences in health care costs are largely driven by differences in inpatient care use. Using data from hospitalizations and infants born in Massachusetts from the Massachusetts Pregnancy to Early Life Longitudinal Data System 1998-2002, Weiss et al. (2009) reported that children with isolated OFC were hospitalized about eight days longer on average than children without OFC during the first two years of life, while those with non-isolated OFC were hospitalized longer by about 22 days ${ }^{13}$. Using hospital discharge data linked to the Florida Birth Defects Registry from 1998-2006, Razzaghi et al. reported that hospital costs during the first two years of life were significantly higher for children with non-isolated OFC than isolated OFC, and that children born low birth weight with OFC had higher birth hospitalization costs than OFC alone ${ }^{13}$, potentially related to additional services needed. Finally, while health care costs have been consistently rising in the United States over the past few decades, inpatient expenditures for children with OFC may be rising at faster rate than overall inpatient spending ${ }^{27}$. A major limitation of previous studies related to the cost of care, specifically inpatient costs, are largely focused on children under the age of 10 and do not examine the impacts of out of pocket costs on families. Additionally, there is a lack of studies on costs related to outpatient services. As a result, it is unclear what that actual costs of OFC care are in the United States. More research is needed in this area.

\section{Health Insurance Coverage}

The increased need for health care services and the higher expenditures among children with OFC highlight the importance of comprehensive insurance plans that cover needed medical, surgical, dental, speech therapy and other developmental/therapeutic services for children with OFC. However, national estimates of access of children with OFC to comprehensive insurance plans are lacking, and estimates based on single states, such as North Carolina, are not generalizable to the overall population in the United States. Prior research suggests that lack of or inadequate insurance are important barriers to accessing all needed health care services. Cassell et al. assessed maternal perceptions of accessibility to health care services for children with OFC in North Carolina, using a state-wide, populationbased birth defects registry and parental survey data. Mothers reported insurance payment caps, inadequate insurance coverage, especially for speech therapy, and high out-of-pocket costs, as main barriers to care in this study ${ }^{28}$.

Using the North Carolina birth defects registry and Medicaid data for children with OFC born in 1995-2002, Cassell et al. (2009) examined timeliness of primary surgical repair of OFC within the first 18 months of life. The authors found that most children $(\sim 78 \%)$ had timely primary surgical repair, although nearly one fifth did not have repair within there commend period $^{29}$. Using national-level data, another study reported that children with cleft palate who were publicly insured had surgical repair statically later than those who are privately insured by about 1.2 weeks on average ${ }^{30}$.

In addition to timeliness of cleft repair, a sizeable proportion of children with OFC may have problems accessing dental care. A survey of parents with children cared for by a craniofacial team in Missouri found children insured by Medicaid had greater difficulty in accessing dental care than those with private insurance ${ }^{31}$. Another study in Alabama that interviewed parents of children with special health care needs, including children with OFC, about their perceptions of accessibility to dental care, reported that $35 \%$ of surveyed parents indicated they had difficulties obtaining dental care for their children, partly due to coverage constraints under Medicaid ${ }^{32}$. Studies examining barriers to care related to health insurance have contributed meaningful knowledge in this area, however there are important limitations to address. Previous research is largely focused on young children, despite the need for comprehensive healthcare services throughout the lifespan, and population-based studies are needed to increase the generalizability of research findings.

\section{Access to Interdisciplinary Care}

Interdisciplinary care, involving multiple health care professionals and specialists across 
various services needed by children with OFC (e.g. surgical, dental, speech, and psychological services) is generally recommended ${ }^{6}$. The 1987 U.S. Surgeon General report highlighted the concept of interdisciplinary care for children with special needs, which helped motivate efforts at the American Craniofacial-Cleft Palate Association (ACPA) to develop team-based parameters of care, which was first published in $1993^{33,34}$. The interdisciplinary approach is the standard of care for treating to children with OFC ${ }^{35}$. Team based, interdisciplinary care allows for coordinated care among multiple specialties to facilitate providing necessary treatments at the appropriate age and in the right sequence.

Understanding access to interdisciplinary care is therefore important given its generally perceived value for health care delivery for children with OFC. Distance to cleft care is a potentially relevant factor in access to team care although empirical research is limited. Cassell et al. (2013) reported that close to half of surveyed mothers of children with OFC in North Carolina traveled over an hour to receive cleft care for their child, although the study could not separate between team versus non-team care ${ }^{22}$. Even though two thirds of the study's respondents did not consider distance to medical care to be a problem, travel time was associated with reporting problems in accessing cleft care.

\section{Training of Community-Based Providers}

In addition to team care, children with oral clefts receive care from community-based providers, who may or may not be able to consult with professionals on cleft teams about treatment milestones and coordinating care. In the absence of team care, the extent to which community-based providers are experienced in treating children with OFC is especially critical to ensure access to adequate care. However, very few studies have evaluated the amount and quality of training community-based providers receive in caring for children with OFC. One study reported that primary care physicians surveyed in Arkansas, lowa, and New York were comfortable with providing routine services to children with OFC, but they are less comfortable with providing cleft-specific services, specifically dental services ${ }^{36}$. A study of community or thodontists in the state of Washington reported that only one fifth of respondents had provided care to more than three patients with OFC within three years from the survey, suggesting that the majority did not frequently provide care to patients with OFC ${ }^{37}$. One study that surveyed orthodontic residents and practicing orthodontists reported that nearly $64 \%$ and $83 \%$ of study participants, respectively, reported that they intended to treat individuals with cranio facial anomalies in the future ${ }^{38}$. In another survey of orthodontic residents, $53 \%$ responded yestointending to treat individuals with OFC or craniofacial anomalies in the future, even though $82 \%$ reported that their programs included training in treating patients with those conditions $^{39}$.

Two studies found that less than two thirds of the orthodontic residents they surveyed responded positively or firmly when asked about whether they intended to treat patients with craniofacial anomalies in the future ${ }^{38,39}$. Another study based on interviews of parents of children with special health care needs (including children with OFC) in Alabama, found that parents reporting difficulty obtaining dental care partly attributed that to lack of providers with adequate training to treat children with special health care needs ${ }^{21}$. Similarly, school-based speech-language pathologists have reported concern about being adequately prepared to care for individuals with OFC once in practice ${ }^{40}$. In 2008, a study found only two-thirds of speech-language graduate training programs included a course on OFC and a minority of students participate in clinical practicums and trainings related to $\mathrm{OFC}^{41}$.

\section{Socio demographic Factors}

Despite an extensive literature on socio demographic disparities in health and health care use in the United States, the empirical evidence on such disparities in health services use and outcomes among children with OFC remains fairly scant. Abbott et al. found that non-White children had cleft palate repair surgeries at an older age than White children, by about 2.6 weeks for Black children, 1.5 weeks for Hispanic children, and 3.5 weeks for children of other race/ethnicity ${ }^{30}$. Similarly, a retrospective chart review study of 233 patients in an urban cleft referral center found that minority status was associated with delayed timing of alveolar bone grafting surgery ${ }^{42}$. The study also found delayed alveolar bone grafting among AfricanAmerican and Hispanic patients by nearly a year compared to Whites, suggesting substantial racial/ethnic disparities in receiving this procedure. Cassell et al. (2009) also found that among children covered by Medicaid in North Carolina, Black children were less likely to 
receive timely primary surgical cleft repair than White ${ }^{29}$. They also found lower odds for timely primary surgery among Hispanic children and children of other race/ethnicity, but these differences were not statistically significant.

A recent study reported enrollment in Medicaid, family instability, minority status, and the need for financial assistance, to be associated with missing appointments for cleft care ${ }^{43}$. Other work has also suggested work related difficulties, stigma and transportation as perceived barriers to care ${ }^{28}$.

\section{Research Needs and Priorities}

Despite providing important knowledge, the extant literature remains inadequate to understand access to care and disparities in health care use and outcomes among children with OFC. We highlight below a few of the main research areas that we believe still need empirical investigation, especially using robust designs and population-based data, to improve the generalizability of current research findings. A general theme is the need to accurately quantify the sources of variation in access to care and health outcomes of individuals with OFC and better understand relationships between access variation and health outcomes.

\section{Out-of-Pocket Costs}

Despite research on total health expenditures among children with OFC, little is known about the extent of out-of-pocket spending and variation across health care and dental services, insurance status and types, and household socioeconomic indicators. Understanding differences in out-of-pocket spending is important to accurately assess financial burden on families and access to needed care.

\section{Variation in State Policy for Coverage and Access}

States vary in their mandates and regulations for covering services needed by children with OFC both in private plans and Medicaid. For instance, some states mandate that children with OFC covered in private plans receive a comprehensive set of services while other states do not mandate such coverage. Similarly, Medicaid programs vary between states in their standards of what is considered medically necessary care and in the generosity of coverage of dental services, such as orthodontic treatment. There is practically no robust empirical research on how these policy variations affect access to care and health outcomes of children with OFC.

Understanding the effects of these policies is critical given that families depend on health insurance to obtain needed services for their children with OFC. Recently, the Affordable Care Act (ACA) mandated covering pediatric preventive and curative dental services, including medically necessary orthodontic treatments in individual and small-group plans as essential health benefits. Understanding the effects of this policy on access to dental care among children with OFC is also important. Furthermore, recent evidence on the ACA impacts on children's health insurance suggests switching from private coverage to Medicaid coverage with the Medicaid expansions for some children, but also an increase in private coverage for other children in Medicaid expanding states ${ }^{44}$. Overall, this evidence suggests an increase in children's coverage rates by nearly three percentage-points due to the ACA in Medicaid expanding states. Understanding changes in coverage rates specifically for children with oral clefts following the ACA and any subsequent changes in health services use is also an important future research direction.

\section{Provider Reimbursement Rates}

Related to the policy variation in coverage mandates and generosity of benefits, provider reimbursement rates also vary between state Medicaid programs. Decker (2015) reported that an increase in Medicaid reimbursement rates for dental services was associated with increased use of dental care in the general population of children and adolescents enrolled in Medicaid $^{45}$.

Buchmueller et al. found that an increase in Medicaid dental reimbursement rates was related to an increase in the number of dental providers who treat publicly covered children ${ }^{46}$. Research on how changes in reimbursement rates specifically affect access of children with OFC is how ever lacking and needed.

\section{Socioeconomic and Demographic Indicators}


Much remains to be understood about differences in access to care by main socioeconomic and demographic factors, such as household income, parental education, employment, race/ethnicity, parental marital status, parental age, and household size. Explaining any observed differences in care and outcomes by these factors would then facilitate developing interventions to reduce disparities in access to care.

\section{Geographic Variation}

The current literature points to some geographic differences in health care access for children with OFC. Understanding these differences nationwide is important for identifying unwarranted sources of variation in access to care and health outcomes. Examining rural/urban disparities is also needed given differential access to cleft teams and specialized care. While travel distance and time have been suggested important factors, additional population-based studies from multiple states are needed to better understand geographic barriers, especially the variation in frequency of needing to travel long distances ${ }^{22}$. Although most states have cleft teams recognized by ACPA, the ratio of affected patients to teams varies substantially between states. Depending on driving distance and provider-networks covered under insurance plans, access to team care can still be a challenge, especially regular use of team care.

\section{Health care Utilization by Service Type}

Prior research in the United States has mainly focused on differences in inpatient care use between children with OFC and the general population, but evidence on other services is limited ${ }^{13,14,25,26}$. More work is needed to understand variation in demand by provider and service type (e.g. primary care, specialized care services, preventive care, medical treatments, mental health interventions, speech therapy, social support, emergency department visits, prescription drugs, and dental care). Related, robust evidence is needed on the effects of alternative care delivery models such as team care versus care through community-based providers or approaches that involve coordination between teams specialized in treating OFC and individual providers on access and patient outcomes.

\section{A Lifelong Perspective}

Research on health service use and access to care among children with OFC in the United States has generally focused on children and adolescents. However, research from other countries, such as Denmark has shown lifelong impacts on use of health services and health outcomes $^{11,47-49}$. Therefore, examining the life course in studies of health services use and access to care in the United States is needed to better understand long-term health care needs and outcomes of affected individuals ${ }^{50}$.

\section{Methodological Considerations}

Addressing the research priorities above raises important methodological issues, which we briefly summarize here. Except for some studies, much of the extant literature has largely been based on data that are not necessarily nationally generalizable. Furthermore, the employed datasets are either cross-sectional or limited in longitudinal follow-up and do not offer comprehensive and adequate measures on all needed domains such as socio economic and demographic factors, and health services use. Obtaining data on nationally representative samples with rich measures of health care use and health outcomes are critical for advancing this research agenda. However, existing national surveys of the United States population do not provide adequate samples of children with birth defects, including OFC, and in many datasets, do not even allow for identification of affected status. State administrative data on healthcare use, such as the state hospital discharge datasets, Medicaid claims data, Agency for Healthcare Research and Quality (AHRQ) Health care Cost and Utilization Project (HCUP) datasets, and data from employed-sponsored plans, such as the Market Scan datasets, provide data on healthcare use and costs and can be useful for examining differences in health care utilization between children with OFC and unaffected children ${ }^{23}$. But, they also have some limitations, including lack of or limited data on household factors and cross-sectional designs and limited longitudinal follow-up (except for children who continue to be enrolled in Medicaid). Therefore, longitudinal surveys on population-based samples of families of children with OFC that can be linked to existing administrative data are needed to enable robust and population-based research on access and outcomes in children with OFC in the United States ${ }^{23}$. Linking data from registries of congenital anomalies to existing administrative datasets such as Medicaid claims would open the door to additional studies of 
health services use using large samples and longitudinal data and improved measurement of OFC types ${ }^{50}$. The majority of states (43) have established systems to track congenital anomalies ${ }^{51}$. To our knowledge however, there have been no linkages across multiple states of data from these registries and other datasets such as public or private insurance claims datasets.

Prior studies are largely descriptive and generally lack a research design that enables causal inference. Findings from these studies therefore largely represent association estimates and not necessarily causal effects. Therefore, improving research designs in future studies to incorporate as much as possible quasi-experimental designs and exogenous variation presents an other opportunity to extend this research field. One example for research focusing on examining differences in health care use and health outcomes between children with OFC and unaffected children is to compare children with OFC to their siblings as an approach to control for family-level differences in unobservable socioeconomic confounders. Prior research on educational achievement have shown that children with OFC have generally lower academic achievement than unaffected children, but not when compared to siblings, suggesting a possibility of unobserved family confounders ${ }^{9,52,53}$. However, one limitation of sibling-comparisons is that differential parental investments in their children can complicate and bias sibling-comparisons. Another limitation is the potential for unaffected siblings to be influenced by having a sibling with an OFC ${ }^{52}$. Nonetheless, comparing to siblings when possible in addition to the general population allows for a more comprehensive assessment of the impacts of OFC on health and health care outcomes. Siblings comparisons on health services use and healthout comes can be done based on data linkages between birth certificates, registries of congenital anomalies, and state administrative data on Medicaid. Finally, developing parameters for quality of care specific to OFC that can be captured in available data sets is needed in order to define optimal care and quantify differences in quality ${ }^{50}$. Quality of care is known to vary extensively in the United States across providers, insurance plans, household factors, and geography. While several of the general quality indicators can be applicable when studying children with OFC, such as hospital readmission within a certain period from discharge, developing meaningful markers of quality for cleft specific services (e.g., surgeries or speech therapy) that can be readily measured and disseminated from existing datasets opens the door to important research opportunities. Several initiatives, such as the Eurocleft studies in Europe and the Americleft in North America have been successful in developing standards for several procedures. Continuing and expanding such efforts is important for facilitating future research on quality of care and outcomes ${ }^{54-56}$.

\section{Conclusion}

Children with OFC require an extensive array of medical, dental, and speech interventions, and adequate access to these services is critical for their health and well-being. We summarized the current knowledge on barriers to care and highlight several research priorities across different themes. Research that examines the impacts of variation between states in mandates for private insurance benefits and generosity in Medicaid coverage, as well as differences in provider reimbursement effects on access to care among children with OFC, which are particularly understudied topics, can generate potentially useful evidence to inform policy interventions that could improve access and health outcomes in this population. Other research directions identified above can also inform future policy making to improve access and reduce barriers for this population.

\section{Acknowledgment}

The authors are grateful to Deborah Kacmarynski, Ana Mercado, Sneha Oberoi, Brandon Viet, and Tanya Wanchek for helpful discussions and comments on earlier versions.

\section{Funding information}

Earlier work on reviewing and summarizing the literature on this topic was funded by \#5U38DD000868 from the National Center on Birth Defects and Developmental Disabilities, Centers for Disease Control and Prevention(CDC). The findings and conclusions in this report are those of the authors and do not necessarily represent the official position of the CDC. 


\section{References}

1. Mossey PA, Little J, Munger RG, Dixon MJ, Shaw WC. Cleft lip and palate. Lancet. 2009; 374(9703):1773-1785.

2. Mai CT, Cassell CH, Meyer RE, et al. Birth defects data from population-based birth defects surveillance programs in the United States, 2007 to 2011: highlighting orofacial clefts. Birth Defects Res A Clin Mol Teratol. 2014;100(11):895-904.

3. Parker SE, Mai CT, Canfield MA, et al. Updated National Birth Prevalence estimates for selected birth defects in the United States, 2004-2006. Birth Defects Res A Clin Mol Teratol. 2010;88(12): 1008-1016.

4. Canfield MA, Mai CT, Wang $\mathrm{Y}$, et al. The association between race/ethnicity and major birth defects in the United States, 1999-2007. Am J Public Health.2014;104(9):e14-e23.

5. Watkins SE, Meyer RE, Strauss RP, Aylsworth AS. Classification, epidemiology, and genetics of orofacial clefts. Clin Plast Surg.2014;41(2):149-163.

6. Jones MC. Parameters for Evaluation and Treatment of Patients With Cleft Lip/Palate or Other Craniofacial 16 Differences. Cleft Palate Craniofac J. 2018;55(1):137-156.

7. Nackashi JA, Dedlow ER, Wood-Dixon V. Health care for children with cleft lip and palate: comprehensive services and infant feeding In: Wyszynski DF, ed. Cleft lip and palate: from origin to treatment. Oxford University Press, USA;2002:303-316.

8. Knight J, Cassell CH, Meyer RE, Strauss RP. Academic outcomes of children with isolated orofacial clefts compared with children without a major birth defect. Cleft Palate Craniofac J.2015;52(3):259-268.

9. Wehby GL, Collet B, Barron S, et al. Academic achievement of children and adolescents with oral clefts. Pediatrics.2014;133(5): 785-792.

10. Tyler MC, Wehby GL, Robbins JM, Damiano PC. Separation anxiety in children ages 4 through 9 with oral clefts. Cleft Palate Craniofac J.2013;50(5):520-527.

11. Wehby GL, Tyler MC, Lindgren S, et al. Oral clefts and behavioral health of young children. Oral Dis.2012;18(1): 74-84.

12. Boulet SL, Grosse SD, Honein MA, Correa-Villasenor A. Children with orofacial clefts: health-care use and costs among a privately insured population. Public Health Rep.2009;124(3):447-453.

13. Razzaghi H, Dawson A, Grosse SD, et al. Factors associated with high hospital resource use in a population-based study of children with orofacial clefts. Birth Defects Res A Clin Mol Teratol. 2015;103(2):127-143.

14. Weiss J, Kotelchuck M, Grosse SD, et al. Hospital use and associated costs of children aged zero-totwo years with craniofacial malformations in Massachusetts. Birth Defects Res A Clin Mol Teratol 2009;85(11):925-934.

15. Nelson PA, Kirk SA, Caress AL, Glenny AM. Parents' emotional and social experiences of caring for a child through cleft treatment. Qual Health Res.2012;22(3):346-359.

16. Nidey N, Moreno Uribe LM, Marazita MM, Wehby GL. Psychosocial well-being of parents of children with oral clefts. Child Care Health Dev.2016;42(1):42-50.

17. Broder HL, Wilson-Genderson M, Sischo L. Health disparities among children with cleft. Am J Public Health.2012;102(5):828-830.

18. Damiano P, Tyler M, Romitti PA, et al. Demographic characteristics, care, and outcomes for children with oral clefts in three states using participants from the National Birth Defects Prevention Study. Cleft Palate Craniofac J.2009;46(6):575-582.

19. Damiano PC, Tyler MC, Romitti PA, et al. Health-related quality of life among preadolescent children with oral clefts: the mother's perspective. Pediatrics.2007;120(2):e283-e290.

20. Wehby GL, Cassell $\mathrm{CH}$. The impact of orofacial clefts on quality of life and healthcare use and 7 costs. Oral Dis.2010;16(1):3-10.

21. Al Agili DE, Roseman J, Pass MA, Thornton JB, Chavers LS. Access to dental care in Alabama for children with special needs: parents' perspectives. J Am Dent Assoc.2004;135(4):490-495.

22. Cassell $\mathrm{CH}$, Krohmer A, Mendez DD, et al. Factors associated with distance and time traveled to cleft and craniofacial care. Birth Defects Res A Clin Mol Teratol. 2013;97(10):685-695.

23. Cassell $\mathrm{CH}$, Strassle $\mathrm{P}$, Mendez DD, et al. Barriers to care for children with orofacial clefts in North 
Carolina. Birth Defects Res A Clin Mol Teratol. 2014;100(11):837-847.

24. Yazdy MM, Honein MA, Rasmussen SA, Frias JL. Priorities for future public health research in orofacial clefts. Cleft Palate Craniofac J. 2007;44(4):351-357.

25. Boulet SL, Grosse SD, Honein MA, Correa-Villasenor A. Children with orofacial clefts:health-care use and costs among a privately insured population. Public Health Rep.2009;124(3):447-453.

26. Cassell CH, Meyer R, Daniels J. Health care expenditures among Medicaid enrolled children with and without orofacial clefts in North Carolina, 1995-2002. Birth Defects Res A Clin Mol Teratol. 2008; 82(11):785-794.

27. Basseri B, Kianmahd BD, Roostaeian J, et al. Current national incidence, trends, and health care resource utilization of cleft lip-cleft palate. Plast Reconstr Surg. 2011;127(3):1255-1262.

28. Cassell CH, Mendez DD, Strauss RP. Maternal perspectives: qualitative responses about perceived barriers to care among children with orofacial clefts in North Carolina. Cleft Palate Craniofac J.2012;49(3):262-269.

29. Cassell CH, Daniels J, Meyer RE. Timeliness of primary cleft lip/palate surgery. Cleft Palate Craniofac J.2009;46(6):588-597.

30. Abbott MM, Kokorowski PJ, Meara JG. Timeliness of surgical care in children with special healthcare needs: delayed palate repair for publicly insured and minority children with cleft palate. J Pediatric Surg. 2011;46(7):1319-1324.

31. Becker DB, Lee F, Hill S, et al. A survey of cleft team patient experience in obtaining dental care. Cleft Palate Craniofac J. 2009;46(4):444-447.

32. Al Agili DE, Roseman J, Pass MA, Thornton JB, Chavers LS. Access to dental care in Alabama for children with special needs: parents' perspectives. J Am Dent Assoc. 2004;135(4):490-495.

33. Services UDoHaH. Surgeon General's Report: Campaign 87-Commitment to Family-Centered, Coordinated Care for Children With Special Health Care Needs. Washington, DC:US Department of Health and Human Services, 1987.

34. Association ACP-C. Standards for Approval of Cleft Palate and Craniofacial Teams-Commission on Approval of Teams. 2010. Retrieved from: www. acpa-cpf.org. Standards/Standards 2010 pdf

35. Strauss RP. Cleft palate and craniofacial teams in the United States and Canada: a national survey of team organization and standards of care. The American Cleft Palate-Craniofacial Association (ACPA) Team Standards Committee. Cleft Palate Craniofac J.1998;35(6):473-480.

36. Damiano PC, Tyler MC, Romitti PA, et al. Primary care physician experience with children with oral clefts in three states. Birth Defects Res A Clin Mol Teratol. 2010; 88(12): 1050-1056.

37. Lewis CW, Ose M, Aspinall C, Omnell ML. Community orthodontists and craniofacial care: results of a Washington state survey. Cleft Palate Craniofac J.2005;42(5):521-525.

38. Brown BR, Inglehart MR. Orthodontic care for underserved patients: professional attitudes and behavior of orthodontic residents and orthodontists. Angle Orthod. 2011;81(6): 1090-1096.

39. Noble J, Karaiskos N, Wiltshire WA. Future provision of orthodontic care for patients with craniofacial anomalies and cleft lip and palate. World J Orthod. 2010;11(3): 269-272.

40. Bedwinek AP, Kummer AW, Rice GB, Grames LM. Current training and continuing education needs of preschool and school-based speech-language pathologists regarding children with cleft lip/palate. Lang Speech Hear Serv Sch.2010;41(4):405-415.

41. Vallino LD, Lass NJ, Bunnell HT, Pannbacker M. Academic and clinical training in cleft palate for speechlanguage pathologists. Cleft Palate Craniofac J.2008;45(4):371-380.

42. Silvestre J, Basta MN, Fischer JP, et al. Minority and Public Insurance Status: Is There a Delay to Alveolar Bone Grafting Surgery? Cleft Palate Craniofac J.2017;54(1):e1-e6.

43. Lynn JV, Ranganathan K, Bageris MH, et al. Sociodemographic Predictors of Missed Appointments Among Patients With Cleft Lip and Palate. Cleft Palate Craniofac J.2018: 55(10):1440-1446.

44. Ugwi P, Lyu W, Wehby GL. The Effects of the Patient Protection and Affordable Care Acton Children's Health Coverage. Medical Care.2019;57(2):115-122.

45. Decker SL, Lipton BJ. Do Medicaid benefit expansions have teeth? The effect of Medicaid adult dental coverage on the use of dental services and oral health. J Health Econ. 2015;44:212-225. 
46. Buchmueller TC, Orzol S, Shore-Sheppard LD. The effect of Medicaid payment rates on access to dental care among children. Am J Health Econ.2015.

47. Pedersen MS, Wehby GL, Pedersen DA, Christensen K. Long-term effects of oral clefts on healthcare utilization: a sibling comparison. Eur J Health Econ.2015;16(6):603-612.

48. Pedersen DA, Wehby GL, Murray JC, Christensen K. Psychiatric Diagnoses in Individuals with NonSyndromic Oral Clefts: A Danish Population-Based Cohort Study. PloS one. 2016;11(5):e0156261.

49. Pedersen DA, Hageman I, Wehby GL, Christensen K. Use of Psychotropic Medications and Visits to Psychiatrists and Psychologists among Individuals with Nonsyndromic Oral Clefts: A Population-Based Cohort Study. Birth defects research.2017;109(11): 824-835.

50. Wehby GL, Moreno LM. Oral clefts and well being: a lifelong perspective and an agenda for comparative effectiveness research. J Comp Eff Res.2014;3(1): 23-28.

51. Prevention CfDCa. State-Based Birth Defects Tracking Systems. 2019.

52. Collett BR, Wehby GL, Barron S, et al. Academic achievement in children with oral clefts versus unaffected siblings. J Pediatr Psychol.2014;39(7):743-751.

53. Wehby GL, Collett BR, Barron S, Romitti P, Ansley T. Children with oral clefts are at greater risk for persistent low achievement in school than classmates. Arch Dis Child.2015;100(12):1148-1154.

54. Russell K, Long RE, Jr., Hathaway R, et al. The Americleft study: an inter-center study of treatment outcomes for patients with unilateral cleft lip and palate part 5. General discussion and conclusions. Cleft Palate Craniofac J.2011;48(3):265-270.

55. Mars M, Asher-McDade C, Brattstrom V, et al. A six-center international study of treatment outcome in patients with clefts of the lip and palate: Part 3. Dental arch relationships. Cleft Palate Craniofac J.1992;29(5):405-408.

56. Hathaway R, Daskalogiannakis J, Mercado A, et al. The Americleft study: an inter-center study of treatment outcomes for patients with unilateral cleft lip and palate part 2. Dental arch relationships. Cleft Palate Craniofac J. 2011;48(3):244-251. 